\title{
Comparison of fire danger indices in the Mediterranean for present day conditions
}

\author{
Christos Giannakopoulos ${ }^{(1)}$, Philippe LeSager ${ }^{(2)}$, Marco Moriondo ${ }^{(3)}$, \\ Marco Bindi ${ }^{(4)}$, Anna Karali ${ }^{(1)}$, Maria Hatzaki ${ }^{(1)}$, Effie Kostopoulou ${ }^{(5)}$
}

This paper assesses the ability of two forest fire danger indices to estimate fire danger and to define the beginning and the end of fire season. Two indices are studied: the Canadian Fire Weather Index (FWI) and the Finnish Forest Fire Index (FFI). The indices are designed to meet the needs of particular regions but they have also proved to be suitable for the Mediterranean region. The aim of this study is to assess the skill performance of both indices and identify their strengths and weaknesses. The Canadian FWI depends on temperature, precipitation, relative humidity and wind measurements, while the Finnish FFI relies on potential evaporation and precipitation. Results indicate that, in general, FWI and FFI determine a fairly similar fire danger for a set of weather conditions. Higher correlations are found especially for locations under significant fire danger. The results improve for the lower values of fire danger if a spin up period is used in the computation of FFI. Both indices show similar features especially during summer, but some deviations are typical during early spring and autumn, as FWI probably overestimates the fire danger.

Keywords: Fire Danger Indices, FFI, FWI, Mediterranean forests

\section{Introduction}

Several fire indices have been used to estimate forest fire danger. Their construction varies widely from one index to another, re-

$\square$ (1) Institute for Environmental Research and Sustainable Development, National Observatory of Athens, I. Metaxa \& V. Pavlou, GR-15236 Palaia Pendeli, Athens (Greece); (2) Chemistry and Climate Division, Royal Netherlands Meteorological Institute- KNMI, Wilhelminalaan 10, NL-3732 GK De Bilt (The Netherlands); (3) Institute of Biometeorology of Florence, National Research Council, v. Caproni 8, I-50145 Florence (Italy); (4) DiPSA-Department of Plant, Soil and Environmental Science, University of Florence, p.le delle Cascine 18, I-50144 Florence (Italy); (5) Department of Geography, University of the Aegean, University Hill, GR-81100 Mytilene (Greece)

(a) Christos Giannakopoulos (cgiannak@meteo.noa.gr)

Received: Jan 25, 2012 - Accepted: Jun 19, 2012

Citation: Giannakopoulos C, LeSager P, Moriondo $M$, Bindi $M$, Karali A, Hatzaki $M$, Kostopoulou E, 2012. Comparison of fire danger indices in the Mediterranean for present day conditions. iForest 5: 197-203 [online 2012-08-02] URL:

http://www.sisef.it/iforest/contents? id=ifor $0622-005$

Communicated by: Agostino Ferrara flecting different underlying approaches. In addition, the reliability of an index may depend on the region where it is applied, since indices or their readings are usually fine tuned for specific regions of interest. In the present study, two indices are considered: the Canadian Fire Weather Index (FWI) and the Finnish Forest Fire Index (FFI). The Canadian FWI depends on temperature, precipitation, relative humidity and wind measurements, while the Finnish FFI relies on potential evaporation and precipitation.

In this work, the two above indices are compared through inter-correlation and their ability to define the beginning and the end of the fire season was assessed. The indices skills are evaluated over the Mediterranean region using real fire observations from Italy for the period 1984-2001. The performance of the indices is further estimated in boreal forest environments in Finland by Vajda et al. (2012).

\section{Brief description of the fire indices}

The Canadian Fire Weather Index (FWI) is based on weather readings taken at noon standard time and rates fire danger at the mid afternoon peak from 2:00 - 4:00 pm. The meteorological variables required for its computation are:

- Air temperature (in the shade);

- Relative Humidity (in the shade);

- Wind speed (at $10 \mathrm{~m}$ above ground, averaged over at least 10 minutes);

- Rainfall (for the previous 24 hours);
The FWI System consists of six components: three fuel moisture codes (Fine Fuel Moisture Code, Duff Moisture Code, Drought Code) and three fire behaviour indices (Initial Spread index, Build Up Index, Fire Weather Index). Calculation of the index requires previous day records of the fuel moisture codes. FWI is divided into four fire danger classes:

- Low $(0-7)$;

- Medium (8-16);

- High $(17-31)$

- Extreme $(>32)$.

The calculation of the Finnish Forest Fire Index (FFI) is based on surface moisture estimation of a $60 \mathrm{~mm}$ thick organic surface layer, consisting of litter, moss and humus (Vajda et al. 2012, Venäläinen \& Heikinheimo 2003) and requires the following input:

- Potential evaporation from 24 hours centred on time of calculation;

- Accumulated precipitation for 24 hours.

Previous day records of the above are required to compute the index. From the beginning of winter until the date of complete melting of snow cover, the surface layer is assumed to be saturated and the volumetric moisture of the surface layer can be assumed to be $50 \%$. The follow-up of soil surface moisture starts immediately after the snow has melted. Finally, the surface moisture is scaled to forest-fire index values that vary between 1 and 6 . Based on the six fire danger classes we can define three fire danger levels:

- Low $(1-4)$;

- Medium $(4-5)$

- High $(>5)$

It is noteworthy that both indices reflect similar weather conditions, since a combination of relative humidity, temperature and wind records can determine evaporation rates (Singh \& Xu 1997). Both indices depend on previous day conditions regarding one or more of their components and they both define fire danger classes.

\section{Results and Discussion}

Correlation between fire indices in the Mediterranean

A subset of ERA-40 re-analysis meteorological data is used to compare FWI and FFI through correlation on a wide domain. The subset of data is centred over the Mediterranean region, on a $1^{\circ} \times 1^{\circ}$ grid, and consists of 6-hourly data of temperature, precipitation, evaporation and wind for the year 1961. Daily values of the variables have been utilised to compute the fire indices. Relative humidity required for computing FWI is estimated by the Romanenko equation as suggested by Singh \& Xu (1997). No snow coverage has been considered when compu- 
Fig. 1 - Variation along the year 1961 (horizontal axis) of the daily Pearson's product-moment correlation coefficients (r) between FWI and FFI for the Mediterranean region.

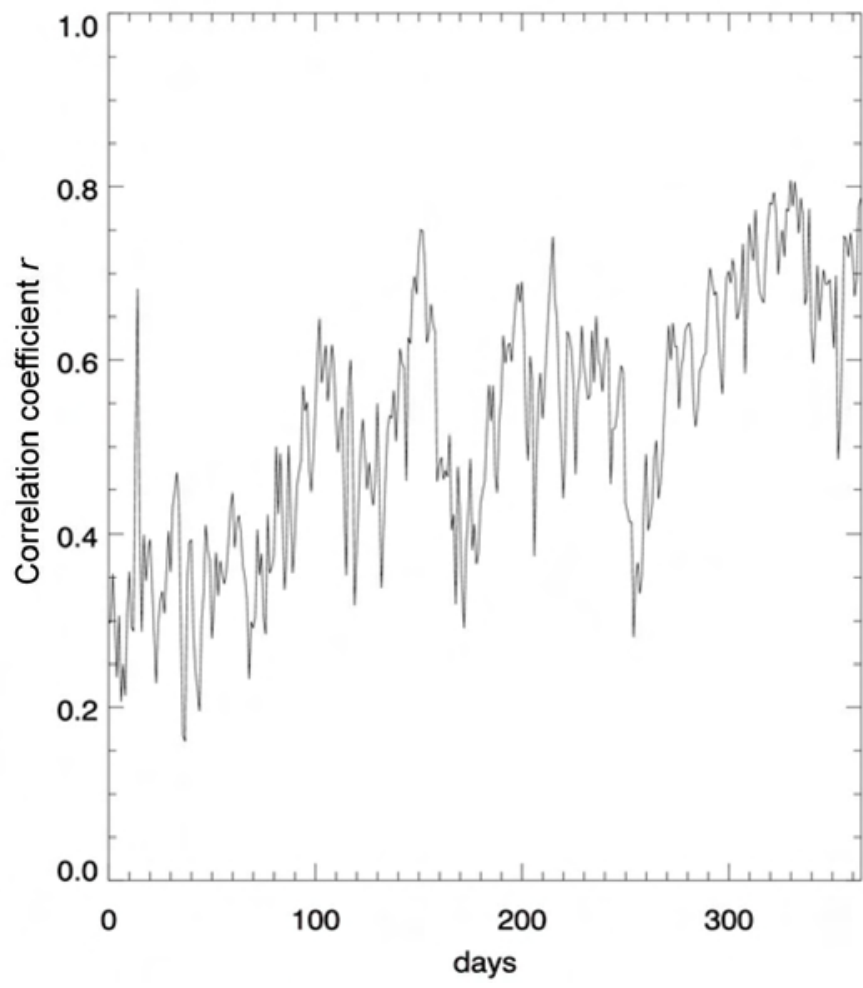

ting FFI. In all following correlations, the sea locations have been neglected.

Considering all locations and all days, the average correlation coefficient (Pearson's $r$ ) between FFI and FWI equals 0.75 , reflecting high correlation between the two indices.

Fig. 1 shows the daily correlations between the two indices for the entire region. The noticeable positive trend might be due to differences in the spin up applied to index computation (one year for FWI, none for FFI), and suggest a biased lowered correlations for the first 100 days of the year. Preliminary investigation showed no dependence of FFI on the spin up period, but further analysis is needed to confirm this statement. Moreover, the particularly low fire danger in winter possibly makes the correlation unreliable.

To get a clearer picture, a spatial analysis was also performed. Fig. 2 shows the local ratio of correlation coefficients (FFI/FWI) for two time periods: full year and summer. Correlation decreases where there is no fire danger, and increases in regions already known for fire occurrences. This is particularly evident in Fig. 3, which shows the local $r$ between danger classes derived from both indices. Correlation is undefined in areas

Fig. 2 - Correlation coefficients between time series of FFI and FWI at each location of the data set. Top: full year; bottom: summer.
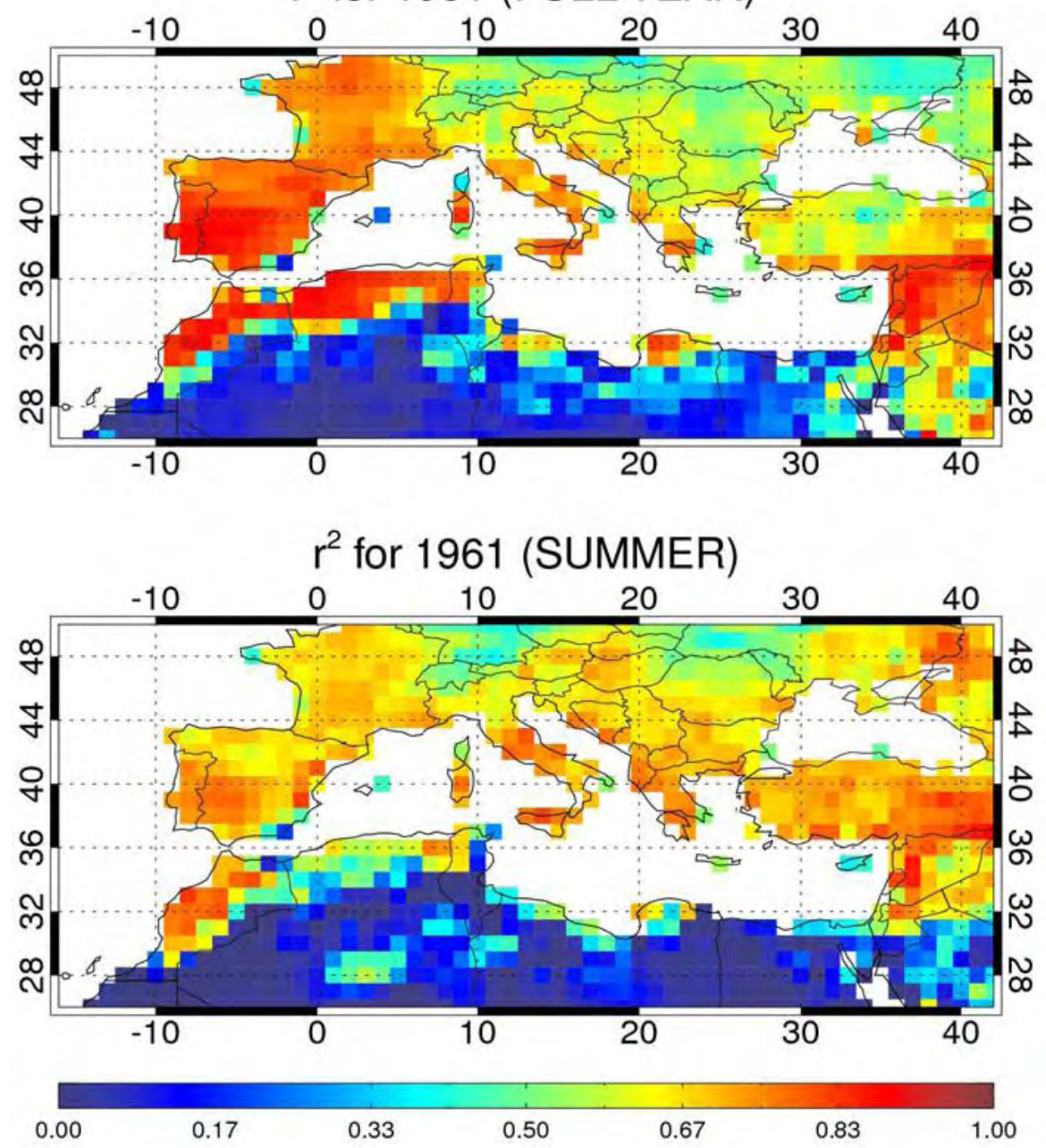
(A)
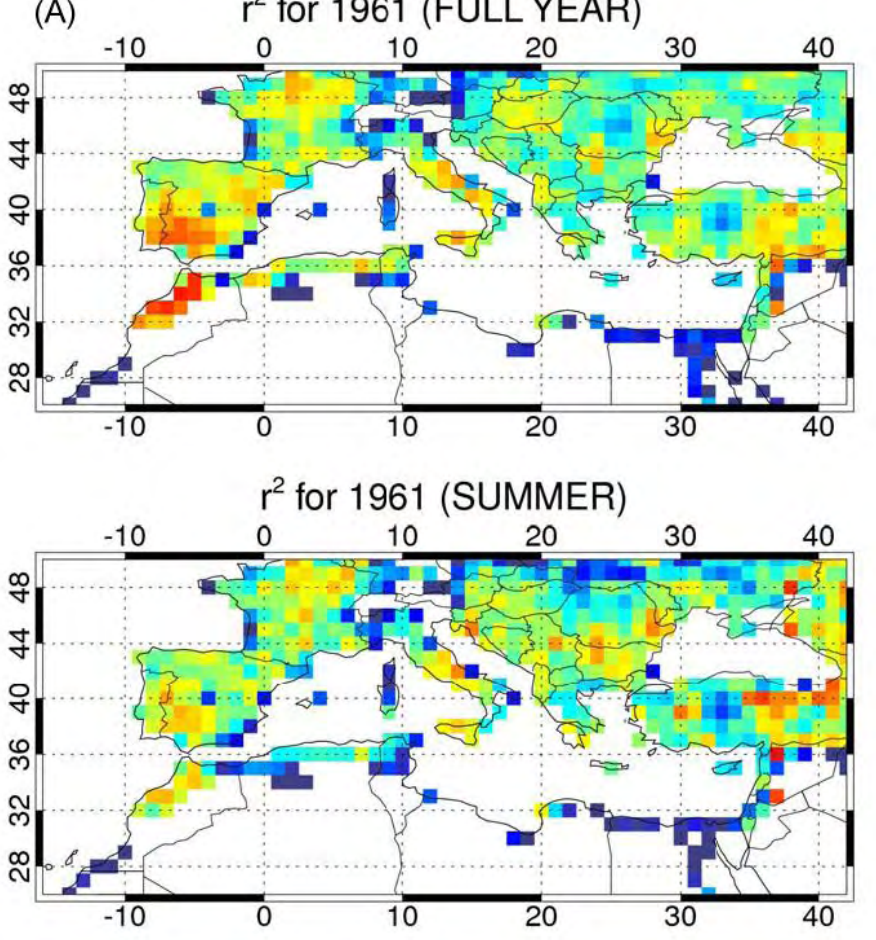

0.00

$r^{2}$ for 1961 (FULL YEAR)
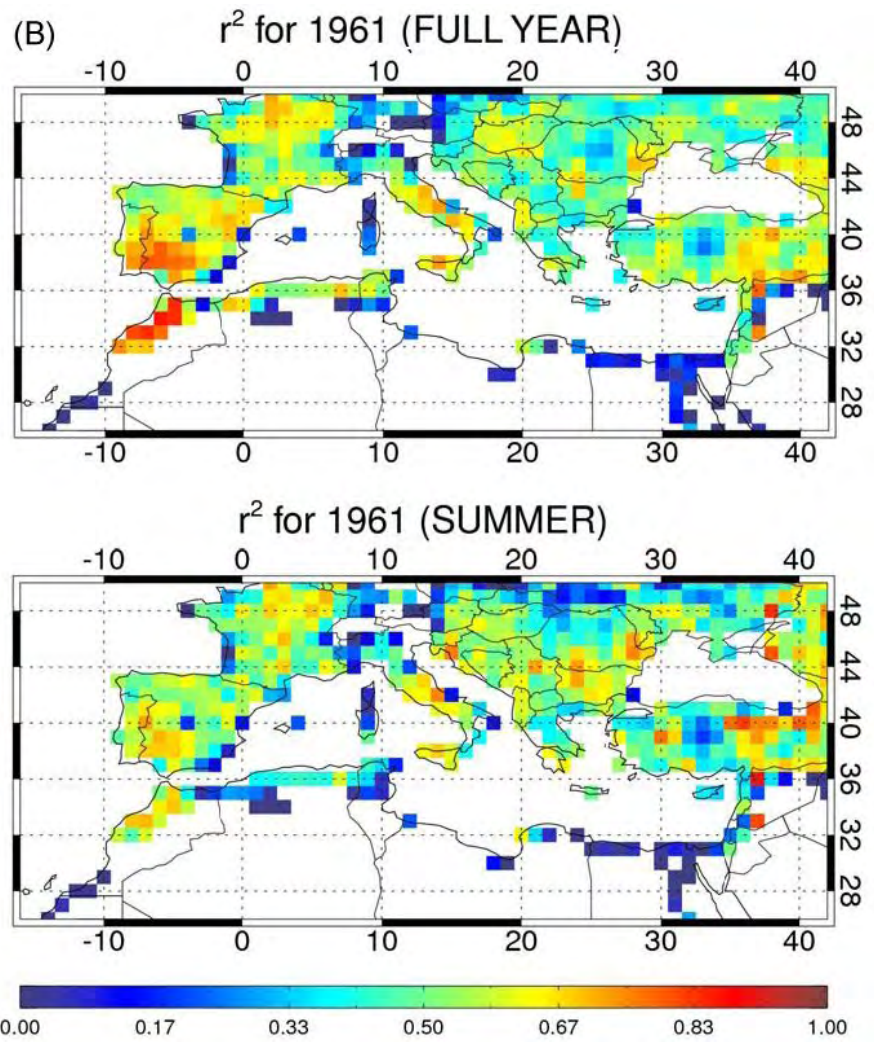

Fig. 3 - Correlation coefficients between the danger classes derived from time series of from FFI (A) and FWI (B) at each location of the data set. Correlation is undefined in areas with no fire danger all over the year (no colour shading displayed).

with no fire danger all year around, and no colour shading is displayed.

Fig. 4 shows the time series at two different locations, one with and one without fire danger. The time series of the indices in the first diagram (Fig. 4a) are characterized by similar behaviours as opposed to those displayed in the second diagram (Fig. 4b), suggesting that, in cases with very low fire danger, a spin up may be needed when com- puting FFI. These findings confirm that regions (or time period) with low fire danger show low correlation (if any) between FWI and FFI. The even lower correlation might be attributed to the lack of a spin up period within the computation of FFI.

\section{Comparison of fire indices against obser-} vations

In this section, regional fire observations (burnt areas, number of fires) from 15 Italian stations (Fig. 5) are compared with fire indices derived from meteorological observations at the same locations. Data are available for the period 1984-2001.

Monthly correlations were estimated between real data and the fire indices and presented in Fig. 6., where blue lines represent the correlation between the two indices. These results provide further evidence to
(A) $\quad$ FFI @ 39N-5E

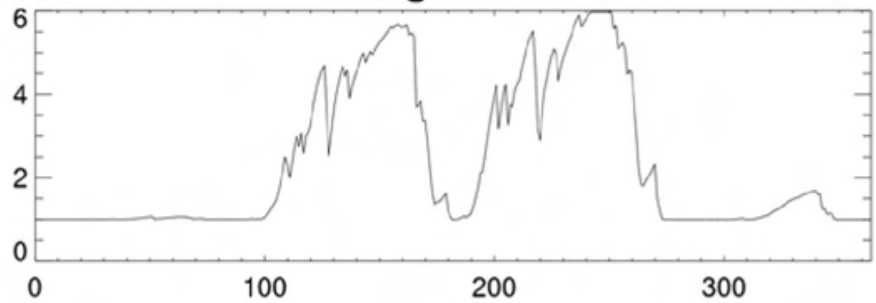

FWI@ @ 39N -5E

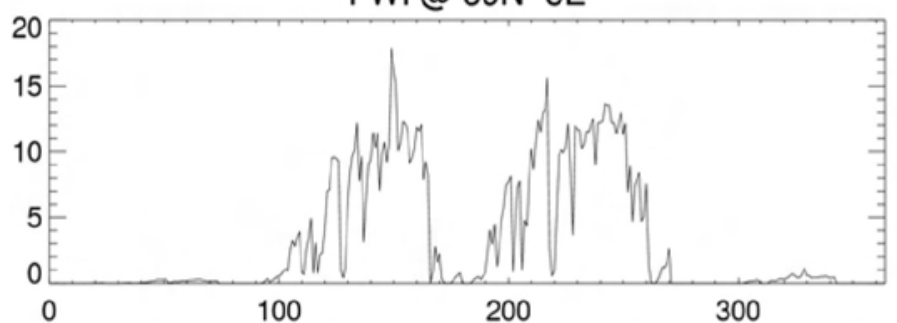

(B)

FFI @ 29N 0E

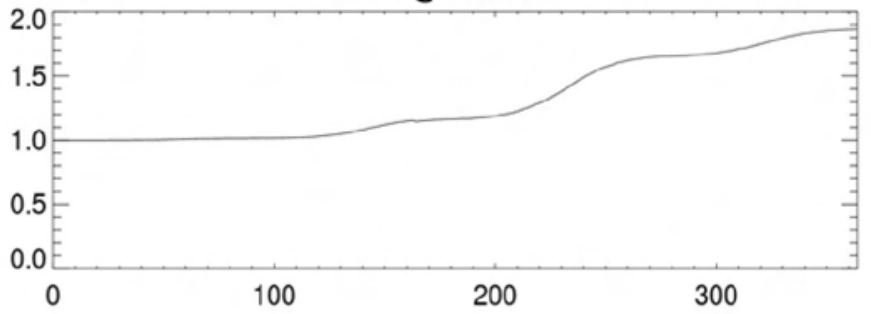

FWI @ 29N 0E

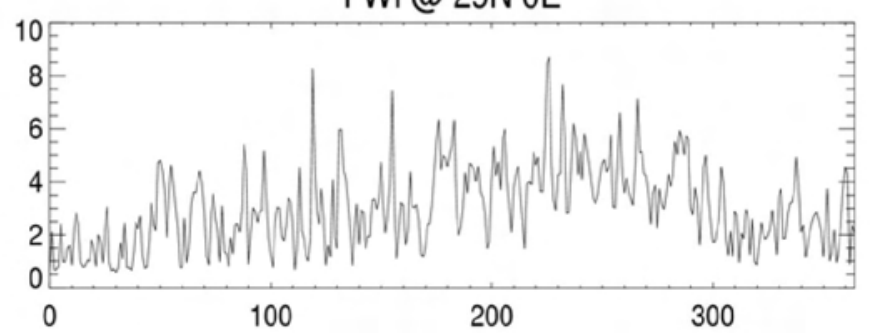

Fig. 4 - Typical time series of FFI and FWI in regions with (A) and without (B) fire danger. 
support the findings from previous section. Note that a spin up period is automatically applied to FFI, since more than one year of data is available. The trend detected in Fig. 1 is not shown in the diagrams of Fig. 6. The black/red lines represent the correlation between FWI/FFI with the number of fires. As expected, the correlation coefficients are rather low, indicating the large levels of uncertainty involved in fire predictions. None of the indices performs particularly well at predicting fire events, since high fire danger is not always associated with fire occurrence. External factors, such as human behaviour (land use policy, fire suppression strategy, etc.) are not taken into account in the indices computation. Fig. 7 shows that areas burnt and fire indices are not correlated in any year.

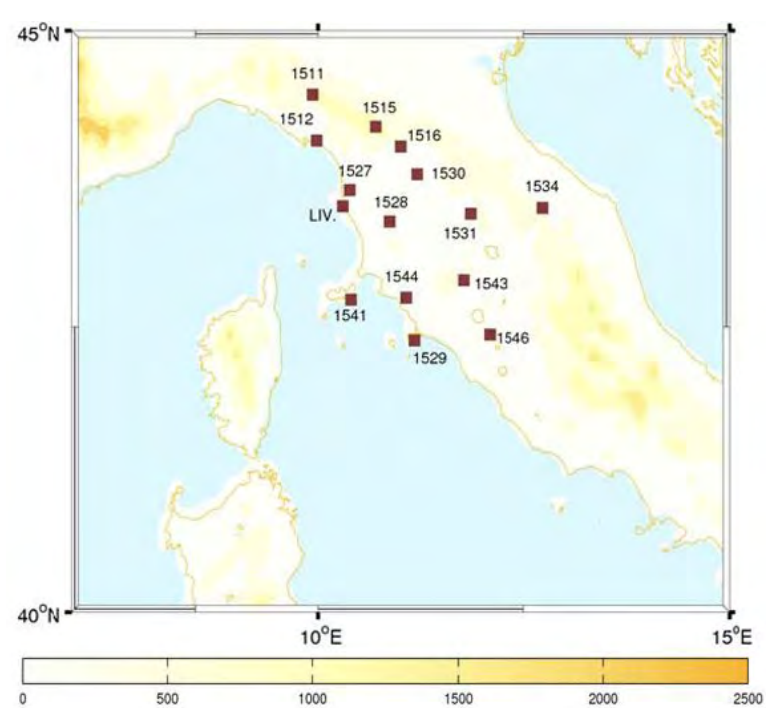

Fig. 5 - Locations of the studied stations in Italy.
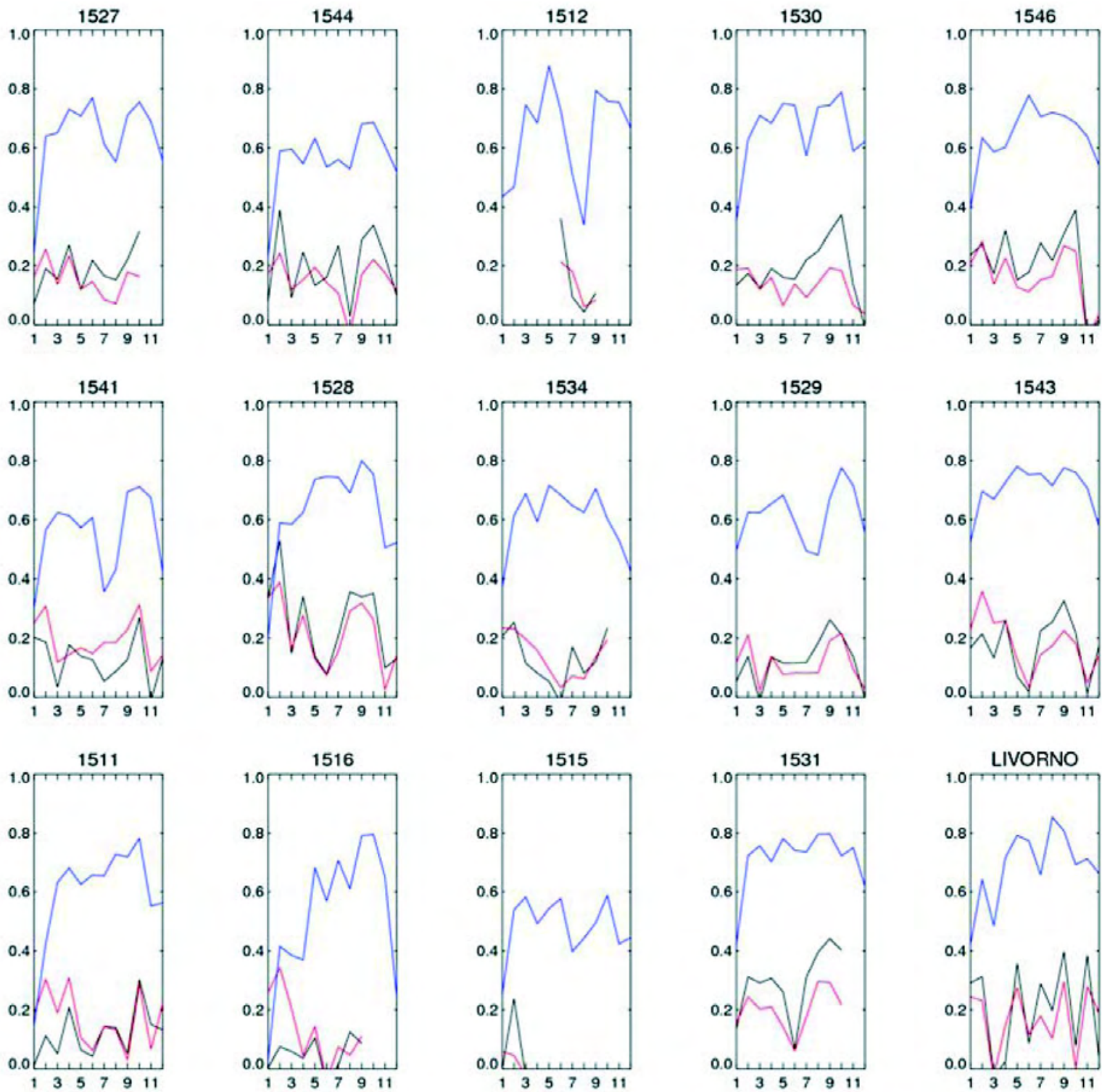

Fig. 6 - Monthly correlations between number of fires and fire indices (FWI: black lines; FFI: red lines) and between the two fire indices (blue lines) for each of the 15 Italian stations. 

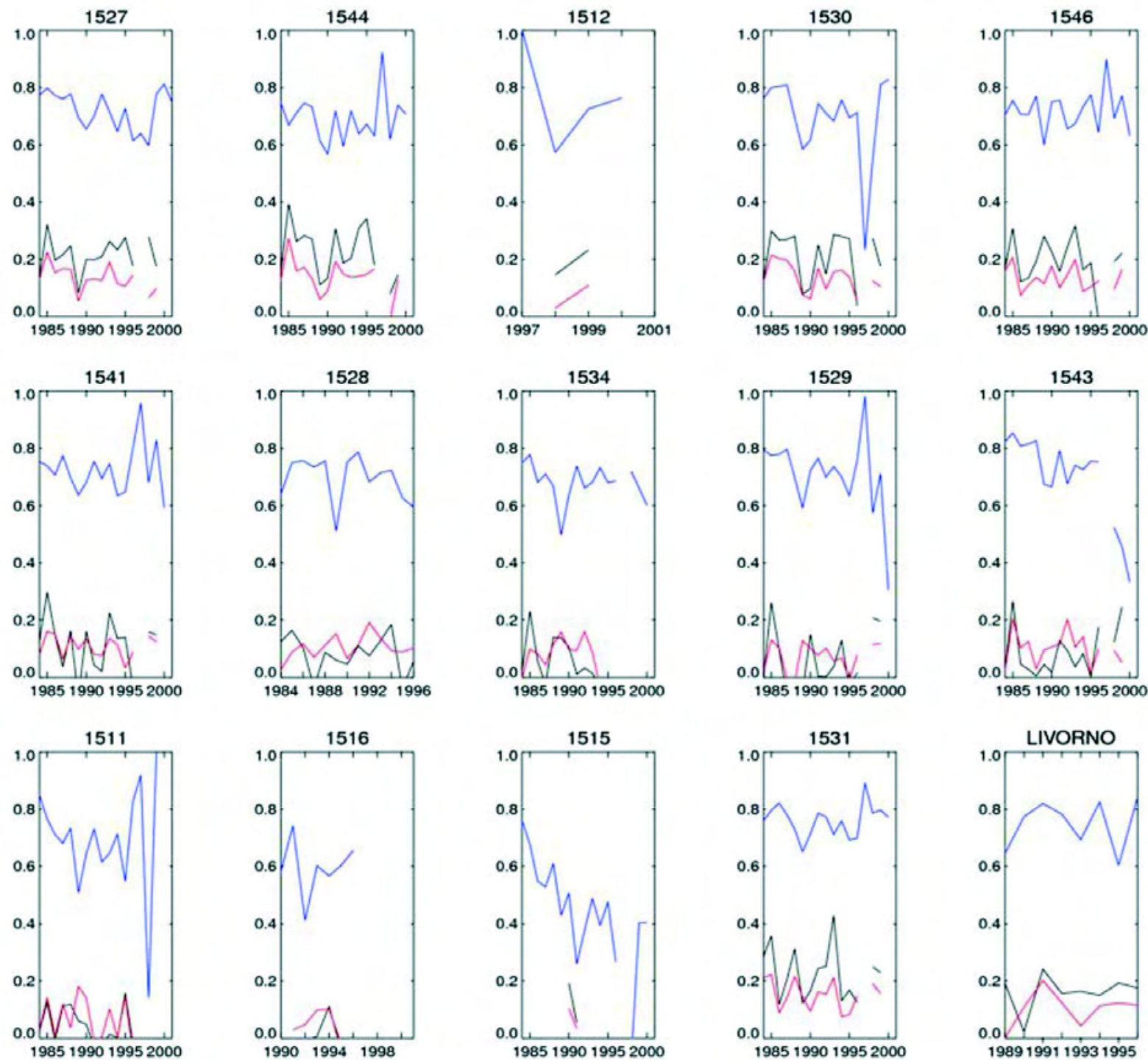

Fig. 7 - Annual correlations between areas burnt and fire indices (FWI: black lines; FFI: red lines) and between the two fire indices (blue lines) for each available year.

Fire indices comparison: determining fire seasons

The ability of both the above indices to define fire seasons was assessed based on the Italian dataset. According to Good et al. (2008) and Moriondo et al. (2006), defining fire seasons with FWI is more robust than with temperature and allows avoiding false alarm. The method consists of:

- Calculation of 7-day running averages to smooth daily variability;

- Use FWI=15 as threshold for beginning and end of the season;

- Defining the beginning of fire season as 2 consecutive weeks with FWI $>15$ (startperiod);

- Defining the end of fire season as 4 consecutive weeks with FWI $<15$ (end-period). The four parameters (threshold, running average period, start- and end-period) were further analysed, so as to become applicable for use with FFI as well. Fig. 8 provides the fire seasons according to both indices at station coded 1544, and for a set of season parameters. The y-axis represents day numbers. A threshold between 4.5 and 5 for FFI gives results similar to FWI (as expected by the danger classes). A running average period between 5 and 7 days seems to be more reliable. Under these conditions, the FFI-derived season begins too early in the early 90's and around 2000. Both indices determine the end of the season at the end of the year 1996. This is definitively too late, and the period used to define the end of the season may need to be shorter.

Fig. 9 shows the fire season at a different station, where FFI performs better than FWI in the definition of a fire season. FWI cannot identify any fire season during the period 1993-1995. On the other hand, the fire season around 2000 is too long with FFI (the full year), something that FWI does not show. Additional investigation is needed to understand the reasons for such differences in this station. The dependence on location calls for a systematic analysis of fire season using larger datasets such as the ERA-40 reanalysis data.

An extensive evaluation of the performance of Finnish Forest Fire Index (FFI) and the Canadian Fire Weather Index (FWI) in boreal forest conditions is provided by Vajda et al. (2012). They examined how the two indices can predict the probability of fire ignition and capability of fire propagation by comparing those with different meteorolo- 


\section{4 - start period $=14$ / end period $=28$}
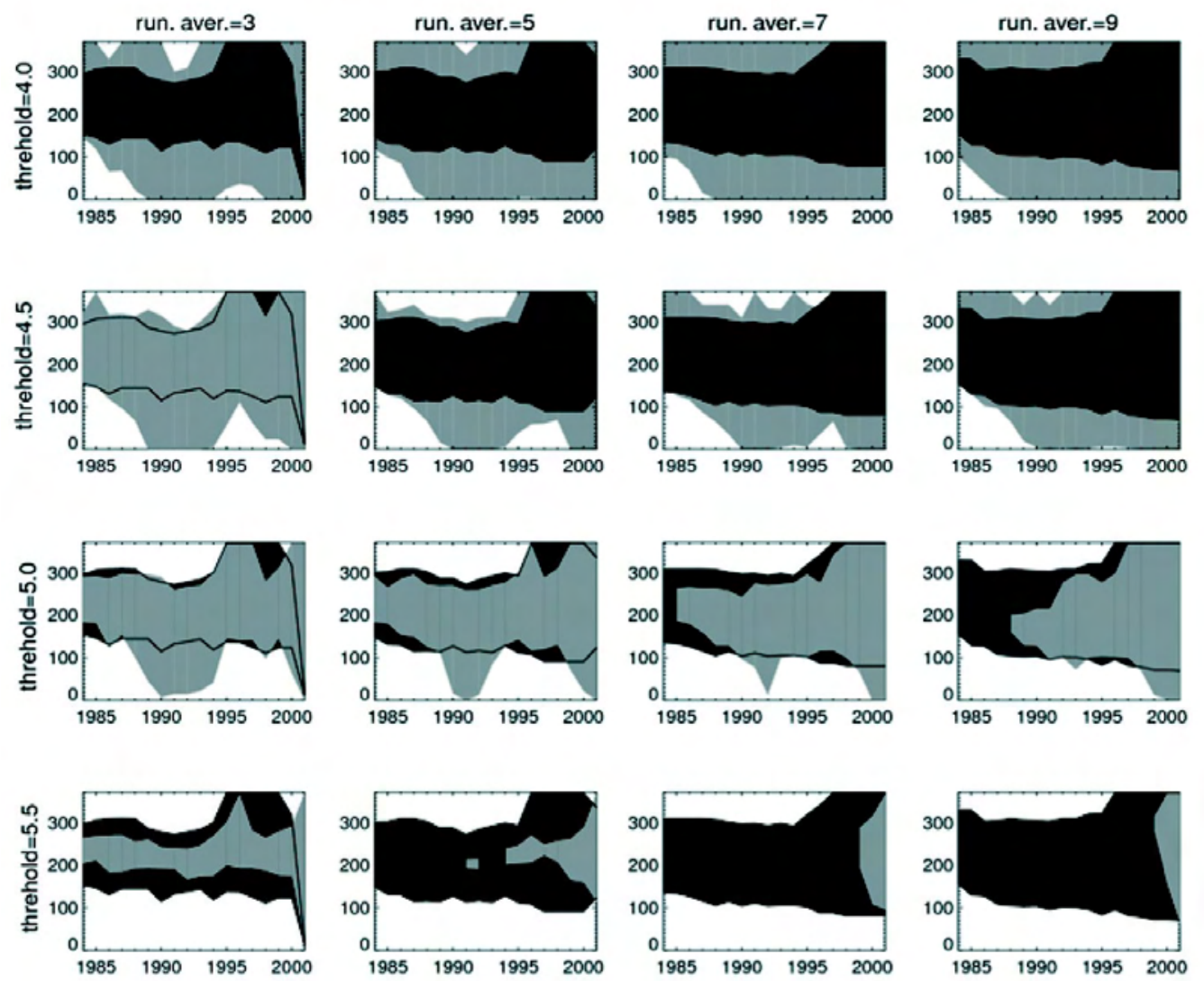

\section{1 - start period $=14$ / end period $=28$}
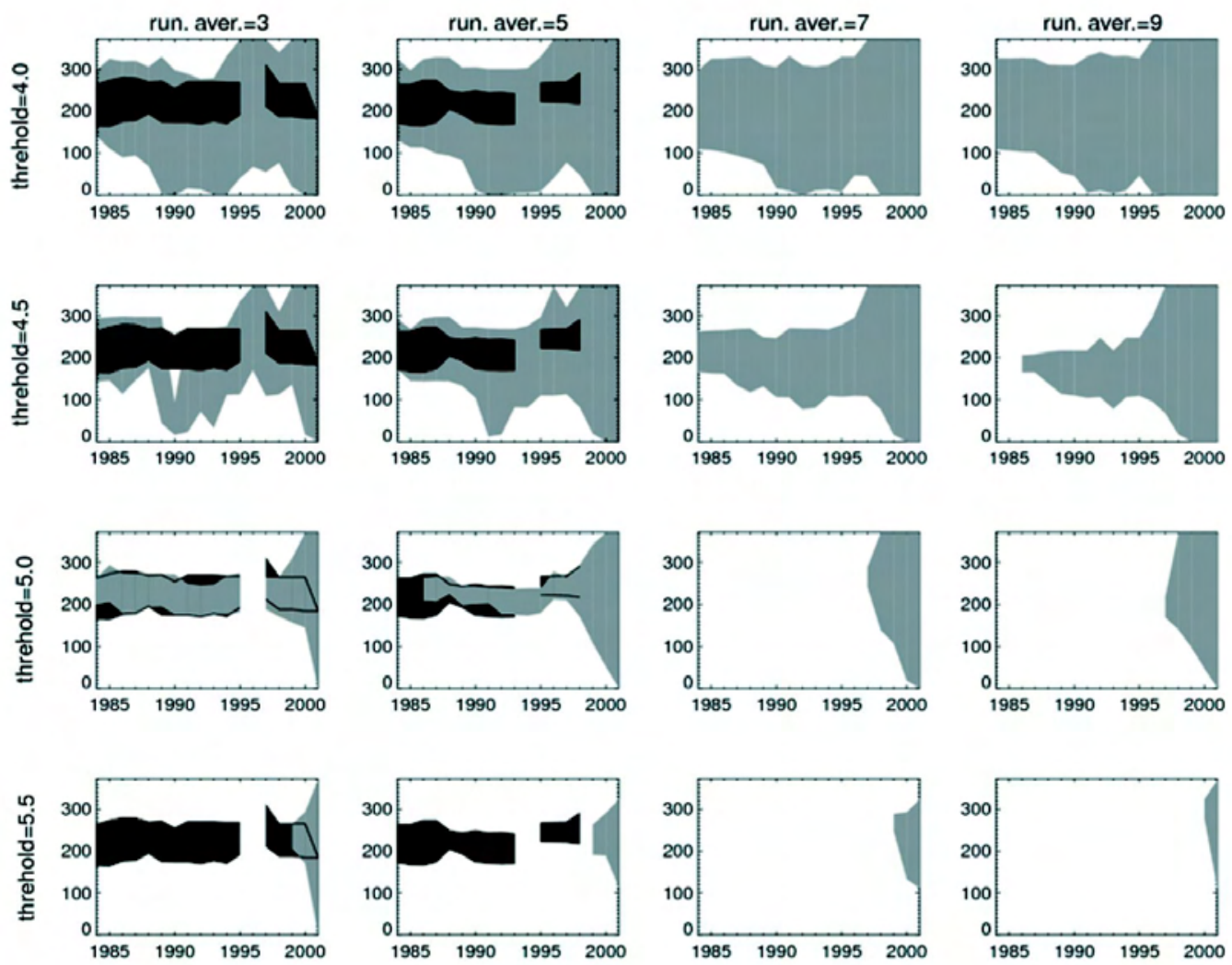

Fig. 8 - Fire seasons according to FWI (black) and FFI (grey) for location code 1544. In all cases, start- and end-periods are 14 and 28 days respectively. In each column, a different running average period is applied to both FWI and FFI. In each row, a different threshold for FFI is used to define the fire period (it is fixed to 15 for FWI).

Fig. 9 - As in Fig. 8, but the results for location coded 1531 are presented here. 
gical variables and observed fire activity.

\section{Conclusions and future plans}

In general, FWI and FFI determine a fairly similar fire danger for a set of weather readings ( $r$ approx. 0.7). Higher correlations are found especially for locations under significant fire danger. The correlation increase for lower values of fire danger if a spin up period is used in the computation of FFI. Similar results were obtained for a boreal forest environment. Both indices show similar features especially during summer, but some deviations are typical during early spring and autumn, as FWI probably overestimates the fire danger. The comparison with meteorological parameters revealed a quick response of this index to environmental changes, especially to rainfall events.

It has to be remarked here that fire indices do not represent fire predictors, though they can be used to define the fire season as an advanced alternative to temperature-based predictions. It is found that fire-season determination based on indices is satisfactory, although fine-tuning is needed in time and space. Namely, cautious adjustment of the start and end periods is required. Neither FFI nor FWI provided a robust definition at any location. Hence, a systematic study using ERA-40 data is planned to be carried out in future study, where FFI, FWI, and particularly their components will be investigated in relation to weather data.

\section{Acknowledgements}

This work was initiated during the course of EU project ENSEMBLES (http://www. ensembles-eu.org) and completed during EU project CLIMRUN (http://www.climrun.eu). Financial support from these projects is greatly acknowledged.

Furthermore, the authors would like to sincerely thank A. Venäläinen and A. Vadja of the Finnish Meteorological Institute for providing the FFI code and useful advices for its use.

\section{References}

Good P, Moriondo M, Giannakopoulos C, Bindi
M (2008). The meteorological conditions associated with extreme fire risk in Italy and Greece: relevance to climate model studies. International Journal of Wildland Fire 17 (2): 155-165. - doi: 10.1071/WF07001

Moriondo M, Good P, Durao R, Bindi M, Giannakopoulos C, Corte Real J (2006). Potential impact of climate change on forest fire risk in Mediterranean area. Climate Research 31(13): 85-95. - doi: 10.3354/cr031085

Singh V, Xu C (1997). Sensitivity of mass transfer-based evaporation equations to errors in daily and monthly input data. Hydrological processes 11:1465-1473. - doi: 10.1002/(SICI)1099-1085 (199709)11:11<1465::AID-HYP452>3.0.CO;2$\mathrm{X}$

Vajda A, Tietäväinen H, Venäläinen A (2012). Evaluation of two fire danger rating methods in the boreal forest environment (Finland). Boreal Environmental Research (Submitted).

Venäläinen A, Heikinheimo M (2003). The Finnish forest fire index calculation system. In: "Early warning systems for natural disaster reduction" (Zschau J \& Kuppers A eds). Springer, Berlin, Germany, pp. 645-648. 